\title{
The D253N Mutation in the Polymerase Basic 2 Gene in Avian Influenza (H9N2) Virus Contributes to the Pathogenesis of the Virus in Mammalian Hosts
}

\author{
Jinfeng Zhang ${ }^{1} \cdot$ Rong Su$^{1} \cdot$ Xiaoyun $\mathrm{Jian}^{2} \cdot$ Hongliang $\mathrm{An}^{1} \cdot$ Ronbing Jiang ${ }^{1} \cdot$ Chris Ka Pun Mok $^{3,4}$
}

Received: 3 September 2018/Accepted: 13 November 2018/Published online: 19 December 2018

(c) Wuhan Institute of Virology, CAS 2018

\begin{abstract}
Mutations in the polymerase basic 2 ( $P B 2$ ) gene of avian influenza viruses are important signatures for their adaptation to mammalian hosts. Various adaptive mutations have been identified around the 627 and nuclear localization sequence (NLS) domains of PB2 protein, and these mutations contribute to the replicative ability of avian influenza viruses. However, few studies have focused on adaptive mutations in other regions of PB2. In this study, we investigated the functional roles of the D253N mutation in PB2 in an H9N2 virus. This mutation was found to affect an amino acid residue in the middle domain of the PB2 protein. The virus with the D253N mutation showed higher polymerase activity and transiently increased viral replication in human cells. However, the mutant did not show significant differences in viral replication in the respiratory tract of mice upon infection. Our results supported that the D253N mutation in the middle domain of PB2, similar to mutations at the 627 and NLS domains, specifically contributed to the replication of avian influenza viruses in human cells.
\end{abstract}

Keywords Avian influenza virus · Mammalian adaptation · D253N · Polymerase basic 2 (PB2) · H9N2

\section{Introduction}

Outbreaks of pathogenic avian influenza virus in humans are associated with high fatality rates and have become a serious public health issue. These viruses can be directly

Chris Ka Pun Mok

ch02mkp@hku.hk

1 Laboratory Medicine Center, Foshan Hospital of Traditional Chinese Medicine, Guangzhou University of Chinese Medicine, Foshan 528200, China

2 Department of Respiratory Medicine, Foshan Hospital of Traditional Chinese Medicine, Guangzhou University of Chinese Medicine, Foshan 528200, China

3 State Key Laboratory of Respiratory Disease, National Clinical Research Center for Respiratory Disease, Guangzhou Institute of Respiratory Health, The First Affiliated Hospital of Guangzhou Medical University, Guangzhou 510000, China

4 HKU-Pasteur Research Pole, School of Public Health, HKU Li Ka Shing Faculty of Medicine, The University of Hong Kong, Hong Kong SAR, China transmitted from avian species to humans and are associated with mortality rates of around 30\%-50\% among infected patients ( $\mathrm{Li}$ and $\mathrm{Cao} 2017$ ). Most of these patients exhibit primary viral pneumonia, with some progressing to acute respiratory distress syndrome (Liem et al. 2009; Gao et al. 2013). Although the pathogenic mechanisms of avian influenza viruses in human are still not clear, these viruses have been found to replicate efficiently in the lower respiratory tract, as supported by the results of clinical, in vitro, ex vivo, and in vivo studies (de Jong et al. 2006; Mok et al. 2013a, b; Chan et al. 2013; Zhou et al. 2013). Moreover, hyperinduction of pro-inflammatory cytokines, which is a hallmark of the infection, is frequently found in patients or animals infected by mammalian-adapted avian influenza viruses (de Jong et al. 2006; Mok et al. 2013a, b; Zhou et al. 2013; Perrone et al. 2008). Lung epithelial cells and macrophages have also been shown to play key roles in the pathogenesis of avian influenza viruses because they are both primary cell targets of these viruses and are the main sources of many pro-inflammatory cytokines upon infection (Cheung et al. 2002; Chan et al. 2005). 
Avian influenza viruses, such as $\mathrm{H} 5 \mathrm{~N} 1, \mathrm{H} 7 \mathrm{~N} 9$, and H9N2, have been frequently isolated from virus-infected patients. Genetic analyses have shown that specific mutations in the polymerase basic 2 ( $P B 2$ ) gene of these viruses are important signatures of their adaptation to mammalian hosts. Various studies have demonstrated that these mutations, which have mostly been identified around the 627 and nuclear localization sequence (NLS) domains of PB2 protein, contribute to the virulence of the viruses by increasing viral replication efficiency or overwhelming immune responses (Mok et al. 2009, 2013a, b; Hatta et al. 2001, 2007). In addition to two well-studied adaptive mutations, E627K and D701N, our previous study identified two mutations, D253N and Q591K, which occurred simultaneously in the $P B 2$ gene of an $\mathrm{H} 9 \mathrm{~N} 2$ virus after serial passages in a mammalian Madin-Darby Canine Kidney (MDCK) cell line (Mok et al. 2011). Although we and others have shown that the Q591K mutation (also located in the 627 domain) in this virus contributes to pathogenesis in our in vitro and in vivo models, no systemic investigations have described the roles of the PB2 D253N mutation (located in the middle protein domain) (Hatta et al. 2007; Wang et al. 2016).

Accordingly, in this study, we further investigated the role of the D253N mutation in $P B 2$ in mammalian hosts when introduced into the H9N2 virus.

\section{Materials and Methods}

\section{Cells}

To obtain primary human macrophages, blood mononuclear cells from healthy donors (Hong Kong Red Cross Blood Transfusion Service) were separated by Ficoll-Paque centrifugation. Monocytes were purified by the adherence method and differentiated into macrophages as previously described (Mok et al. 2009; Wang et al. 2016). Normal human bronchial epithelial (NHBE) cells were purchased from Lonza. The cells were seeded at $1 \times 10^{5}$ cells/well in 24-well plates and differentiated for 21 days with an airliquid interface, as previously described (Wang et al. 2016). Human embryonic kidney $293 \mathrm{~T}$ and MDCK cells were maintained in Eagle's minimal essential medium containing $10 \%$ fetal calf serum and antibiotics.

\section{Polymerase Activity Assay}

A single mutation at $\mathrm{D} 253 \mathrm{~N}$ was introduced into the $\mathrm{PB} 2$ plasmid of the A/Duck/Hong Kong/Y280/97 (H9N2/Y280) virus using a point mutation kit (Roche, USA). The PB2 plasmid was transferred into $293 \mathrm{~T}$ cells monolayers together with PB1, PA, and NP plasmids of the H9N2/Y280 virus as well as the luciferase reporter plasmid (pluci) and the internal control plasmid (phRL-CMV). After $24 \mathrm{~h}$ of incubation, cell extracts were prepared in $500 \mu \mathrm{L}$ lysis buffer. The luciferase levels were assayed with a Luciferase Assay System (Promega, Madison, WI, USA) and detected using a luminometer.

\section{Generation of Recombinant Viruses}

Eight plasmids containing the full genome of the H9N2/ Y280 virus were transfected into 293T cells using TransIT for $48 \mathrm{~h}$. Supernatants were then inoculated into embryonic eggs for $48 \mathrm{~h}$. The titer of the viruses was determined by plaque forming assays in MDCK cells.

\section{In Vitro Experiments}

Primary human macrophages or primary human bronchial epithelial cells were infected with H9N2/Y280 or the PB2 mutant at a multiplicity of infection (MOI) of 2 or 0.01 according to the indicated conditions. Total RNA or supernatants were collected at $3,6,24,48$, and $72 \mathrm{~h}$ postinfection. Evidence of viral replication from the supernatants of the infected cells was determined according to the tissue culture infectious dose $50\left(\mathrm{TCID}_{50}\right)$ in MDCK cells. Induction of cytokine mRNAs and proteins was determined by quantitative reverse transcription-polymerase chain reaction (PCR) and bead-based enzymelinked immunosorbent assay (ELISA; Biolegend), respectively.

\section{Animal Experiments}

Eight 6- to 8-week-old $\mathrm{BALB} / \mathrm{c}$ mice per group were inoculated intranasally with recombinant H9N2 viruses with or without the D253N mutation in PB2. Lethality and weight loss in the infected mice were recorded for 14 days. In the next experiment, three mice per group infected by either the wild-type or mutant PB2 were sacrificed on days 3 and 6 after infection to compare cytokine induction and viral replication in the lungs. The brain, liver, and lungs were isolated and homogenized with $1 \mathrm{~mL}$ phosphatebuffered saline (PBS). The supernatant was collected after centrifugation, and the levels of cytokines and viral replication were determined by bead-based ELISA (Biolegend) and TCID $_{50}$ assays, respectively. Nasal wash was collected by inoculating $200 \mu \mathrm{L}$ PBS into the noses of the mice.

This study protocol was carried out in strict accordance with the recommendations and approval of the Committee on the Use of Live Animals in Teaching and Research of the University of Hong Kong (approval no.: CULATR 2270-10). Humane endpoints for animal experiments and methods were undertaken to minimize potential pain and 
distress. All animals were euthanized using pentobarbital (200 mg/kg, intravenous injection) at the end of the experiments or once they were severely sick and showed more than one of the following signs (score $>1$, as one sign $=1$ ): loss of weight more than $30 \%$, respiratory signs, depression, diarrhea, cyanosis of the exposed skin, edema of the face and head, and neurological signs. No mice fulfilled the above criteria or were euthanized before the end of the experiment.

\section{Quantitative Analysis of Cytokine Levels}

Expression levels of tumor necrosis factor (TNF)- $\alpha$, macrophage inflammatory protein (MIP)- $1 \alpha$, MIP- $1 \beta$, monocyte chemotactic protein (MCP)-1, MCP-3, and interferon$\gamma$-induced protein-10 (IP-10) from the samples were quantitatively determined by flow cytometry-based immunoassay (Biolegend). Twenty-five microliters of each sample was processed according to the manufacturer's protocol. The amounts of cytokines $(\mathrm{pg} / \mathrm{mL})$ in the samples were determined using a BD LSRII (BD Bioscience) and was calculated using the software provided by Biolegend.

\section{Statistical Analysis}

The statistical significance of differences between experimental groups was determined using unpaired, parametric Student's $t$ tests. Differences with $P$ values less than 0.05 were considered significant.

\section{Results}

\section{The H9N2 Virus with the D253N Mutation in PB2 Showed Enhanced Polymerase Activity and Transiently Increased Viral Replication in Human Cells}

Our previous studies showed that the amino acid substitution D253N in the $P B 2$ gene of an avian influenza virus H9N2/G1 resulted in increased polymerase activity and
Fig. 1 The polymerase activity and virus replication of $\mathrm{H} 9 \mathrm{~N} 2 /$ Y280 is enhanced by the D253N mutant in PB2. 293T cells were transfected with plasmids containing H9N2/Y280 $P B 2$, $P B 1, P A$, and $N P$ genes plus a control luciferase reporter plasmid and a viral untranslated region-driven luciferase reporter plasmid. Transfected cells were cultured at A $37{ }^{\circ} \mathrm{C}$ and B $33{ }^{\circ} \mathrm{C}$ for $24 \mathrm{~h}$, and luciferase activity was assayed in cell extracts. Results are the averages of three experiments. The values were statistical analyzed by twotailed, paired $t$-tests. ${ }^{*} P<0.05$. Primary NHBE cells were infected at an MOI of 0.01 with H9N2/Y280 and the PB2 mutant. The viral titers were measured from the supernatants at 24,48 , and $72 \mathrm{~h}$ postinfection using TCID $_{50}$ assays. C $37{ }^{\circ} \mathrm{C}$, D $33^{\circ} \mathrm{C}$. The data are shown as means of three independent experiments. $* P<0.05$.
A

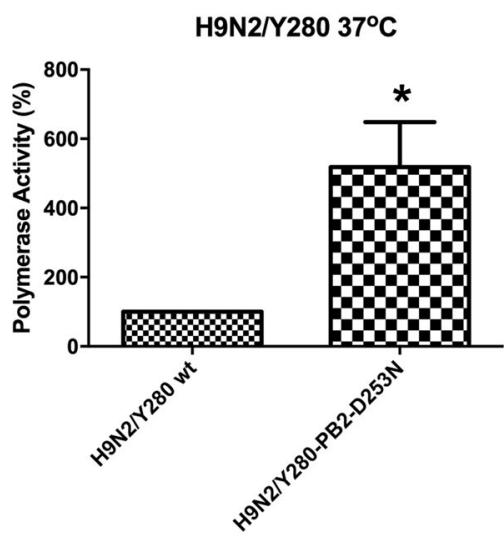

C

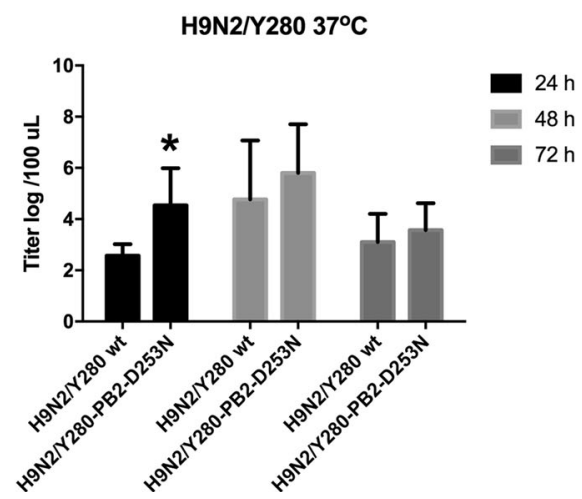

B

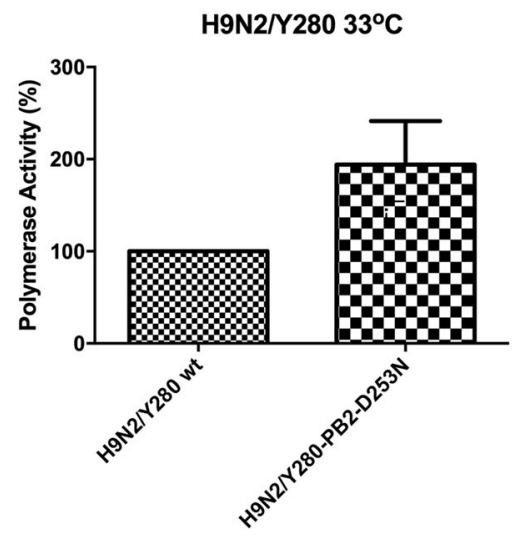

D

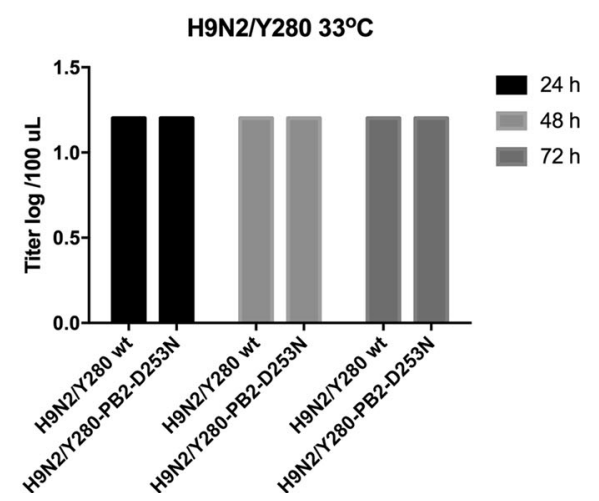


A

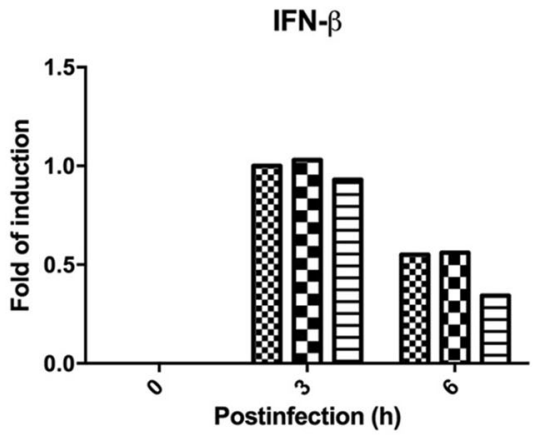

D

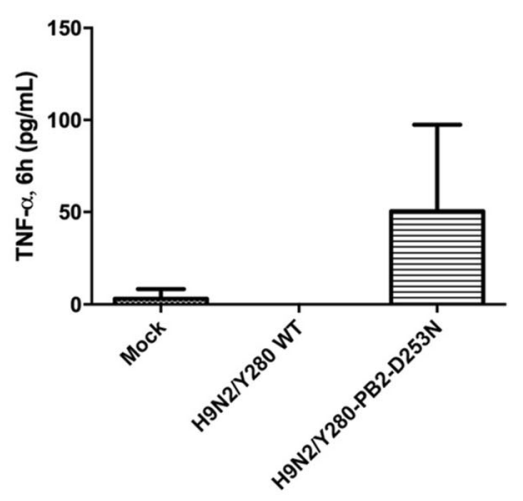

G

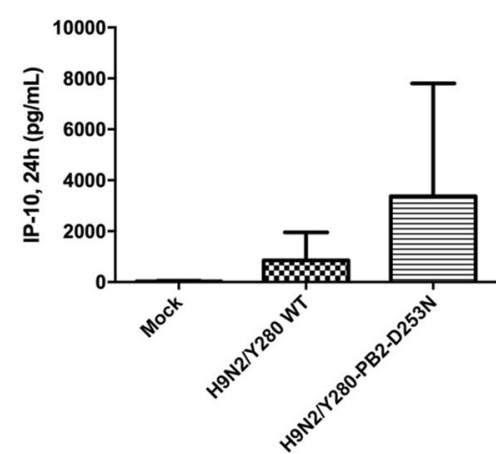

B

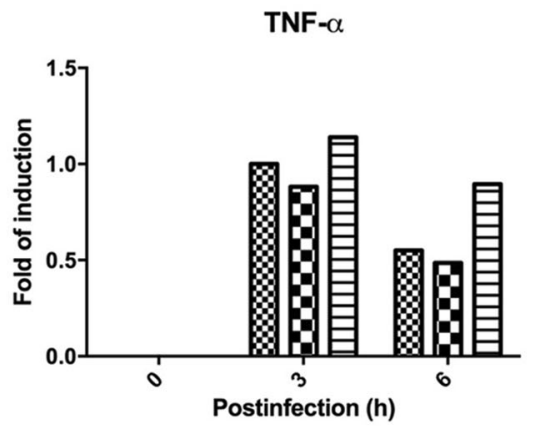

$E$

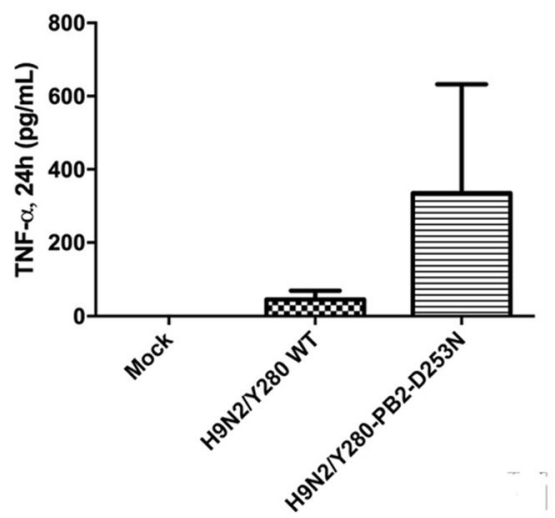

C

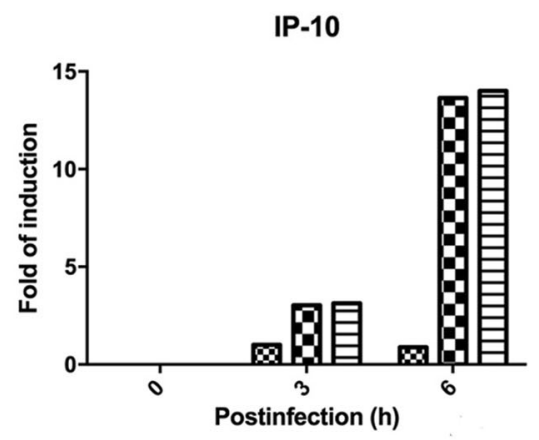

$\mathbf{F}$

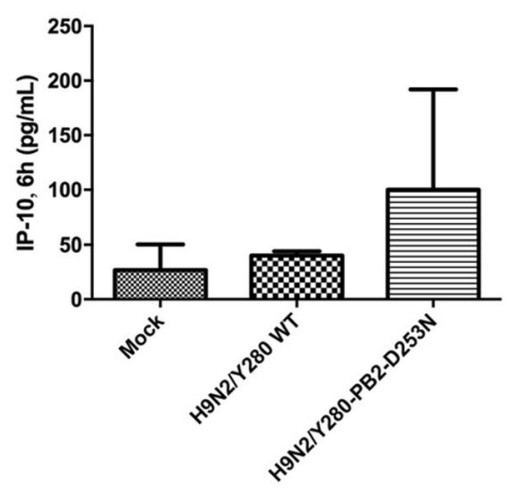

Fig. 2 Induction of cytokine mRNA and protein in primary human macrophages does not enhanced by the PB2-D253N mutation of H9N2/Y280 virus. Primary human macrophages were infected at an MOI of 2 with the H9N2/Y280 virus or the PB2 variant. mRNA was collected at 0,3 , and $6 \mathrm{~h}$ postinfection. The gene copy numbers of (A) $I F N-\beta$, (B) $T N F-\alpha$, and (C) $I P-10$ were analyzed by real-time PCR. The data are shown based on the results of a representative

transiently higher viral replication in human cells (Mok et al. 2011). To determine whether these observations were strain-specific and occurred in one virus strain, we further examined the functions of this mutation in another virus, H9N2/Y280, which belongs to another representative lineage of the H9N2 subtype. We compared the activity of the polymerase complex between wild-type H9N2/Y280 (wt) virus and the mutant virus harboring the D253N donor. Mock: uninfected cells. GAPDH was used as internal control. The supernatants were collected at 6 and $24 \mathrm{~h}$ postinfection. The protein levels of (D) TNF- $\alpha$ (6 h), (E) TNF- $\alpha$ (24 h), (F) IP-10 (6 h), and (G) IP-10 (24 h) were analyzed using an ELISA-based cytomix detection kit. Results are expressed as means \pm standard deviations of three independent experiments. Mock: uninfected cells.

substitution in PB2 in a minigenome reporter assay using human 293T cells. Compared with the polymerase activity of the wt H9N2/Y280, the D253N mutant PB2 showed higher polymerase activity at $37{ }^{\circ} \mathrm{C}$ (temperature of the lower respiratory tract) but not at $33{ }^{\circ} \mathrm{C}$ (temperature of the upper respiratory tract) in $293 \mathrm{~T}$ cells (Fig. 1A, 1B).

Initial infection and onward transmission of an influenza virus depends on efficient viral replication in the human 
respiratory tract. Primary NHBE cells were infected with H9N2/Y280 or the D253N mutant PB2 at an MOI of 0.01 and incubated at either $33{ }^{\circ} \mathrm{C}$ or $37{ }^{\circ} \mathrm{C}$. Higher viral replication was found from the supernatant collected from cells infected with the PB2 mutant at $24 \mathrm{~h}$ postinfection but not at 48 or $72 \mathrm{~h}$ postinfection at $37{ }^{\circ} \mathrm{C}$ compared with those infected by the wt control. No significant differences in viral replication were found between cells infected by the wt and mutant $\mathrm{PB} 2$ at $33{ }^{\circ} \mathrm{C}$ (Fig. 1C, 1D).

\section{The D253N Mutant in PB2 Did Not Contribute to Cytokine Induction in Primary Human Macrophages}

Human macrophages are a primary target of avian influenza virus. Secretion of pro-inflammatory cytokines has been shown to play a role in virus pathogenesis during the infection. Moreover, we previously showed that the single mutation of D253N in PB2 in the H9N2/G1 virus did not enhance cytokine induction in primary human monocytederived macrophages. To further confirm this phenomenon, we compared the level of cytokine induction in macrophages infected with the H9N2/Y280 virus or the D253N mutant. Total mRNA and culture supernatants of virusinfected primary human macrophages were collected and tested using quantitative PCR and ELISA. No significant differences in the mRNA and protein levels of interferon- $\beta$ (IFN- $\beta$ ), IP-10, and TNF- $\alpha$ were found between the wt H9N2/Y280 and PB2 mutant (Fig. 2). Taken together, these findings demonstrated that the D253N mutation in PB2 did not contribute to the upregulation of pro-inflammatory cytokines in primary human macrophages.

\section{The D253N Mutation in PB2 in the H9N2 Virus Did Not Contribute to Viral Replication in the Respiratory Tract of Mice}

We next examined the pathogenicity of the D253N mutant in PB2 using an in vivo model of healthy female BALB/c mice (Fig. 3). No mice died or showed virus dissemination to the brain and liver in both groups (data not shown). Mice infected with the wt H9N2/Y280 virus showed weight loss of approximately $10 \%-12 \%$ within 14 days postinfection. Additionally, mice infected with the D253N mutant showed slightly more weight loss than mice infected with wt virus on days 4-7 (18\%-20\%) (Fig. 3A). However, mice infected with the D253N mutant in PB2 showed no significant differences in viral replication in nasal wash and lung homogenates compared with that in the wt control (Fig. 3B, 3C).

We also compared the induction of pro-inflammatory cytokines in the lungs of mice infected with the wt H9N2/ Y280 virus and the D253N mutant. All wt and PB2 mutants produce higher level of cytokines than uninfected controls. However, mice infected with the PB2 mutant showed comparable levels of pro-inflammatory cytokines (IP-10, MCP3 , MCP-1, MIP- $1 \alpha$, MIP- $1 \beta$, and TNF- $\alpha$ ) in the lungs compared with those in wt controls (Fig. 4A-4F; $P>0.05$ ).

\section{Discussion}

In our previous study, we showed that the D253N mutation occurred together with the Q591K mutation in the PB2 gene (Mok et al. 2011). We and others subsequently demonstrated that the Q591K mutation is an important factor determining the pathogeneses of different avian influenza viruses in

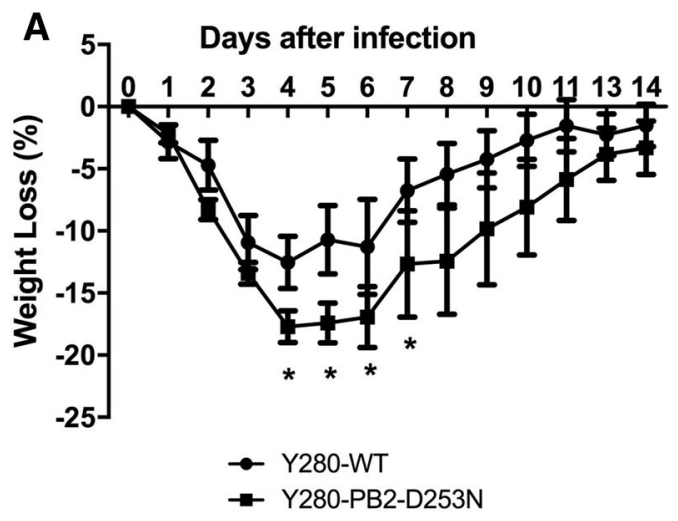

Fig. 3 The PB2-D253N mutation of H9N2/Y280 virus causes more weight loss but not virus replication in mice. Female BALB/c mice were infected intranasally with $1 \times 10^{5} \mathrm{PFU}$ of $\mathrm{H} 9 \mathrm{~N} 2 / \mathrm{Y} 280$ or the D253N mutant in PB2. A The weights of the infected mice were expressed as the percentage change compared with the weight at day 0 . Results from each time point are expressed as means \pm standard deviations of eight mice. $\mathbf{B}$ The nasal wash and $\mathbf{C}$ lungs were
B

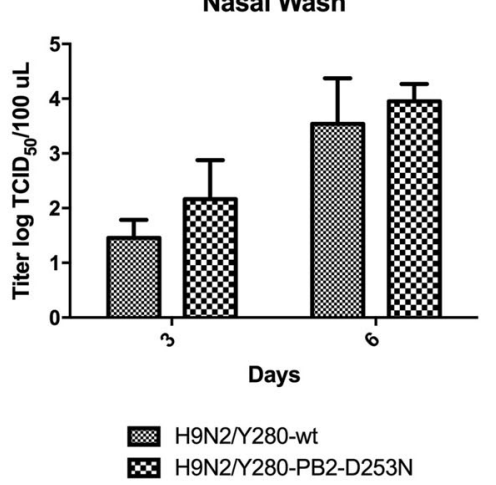

C

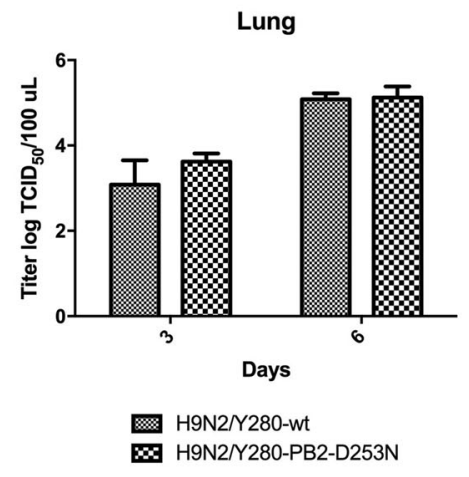

harvested for viral titration at 3 and 6 days postinoculation. Lungs were homogenized in $1 \mathrm{~mL}$ PBS, and $200 \mu \mathrm{L}$ PBS was used as a nasal wash. The results from each group are represented by the average titers of three mice. The viral titers were determined by calculating the $\mathrm{TCID}_{50}$ in MDCK cells. Results from each time point were expressed as means \pm standard deviations. $* P<0.05$. 

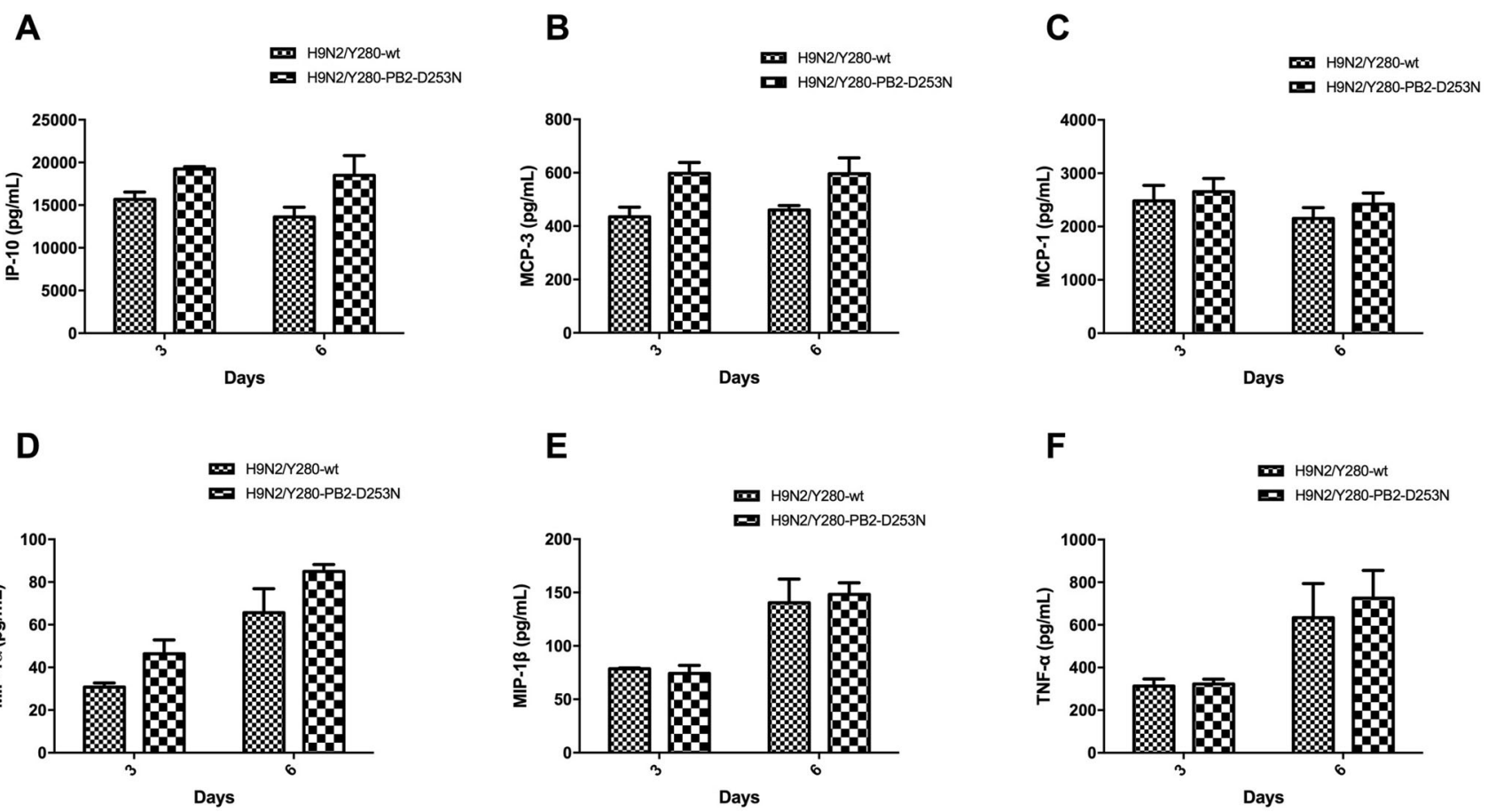

$\mathbf{F}$
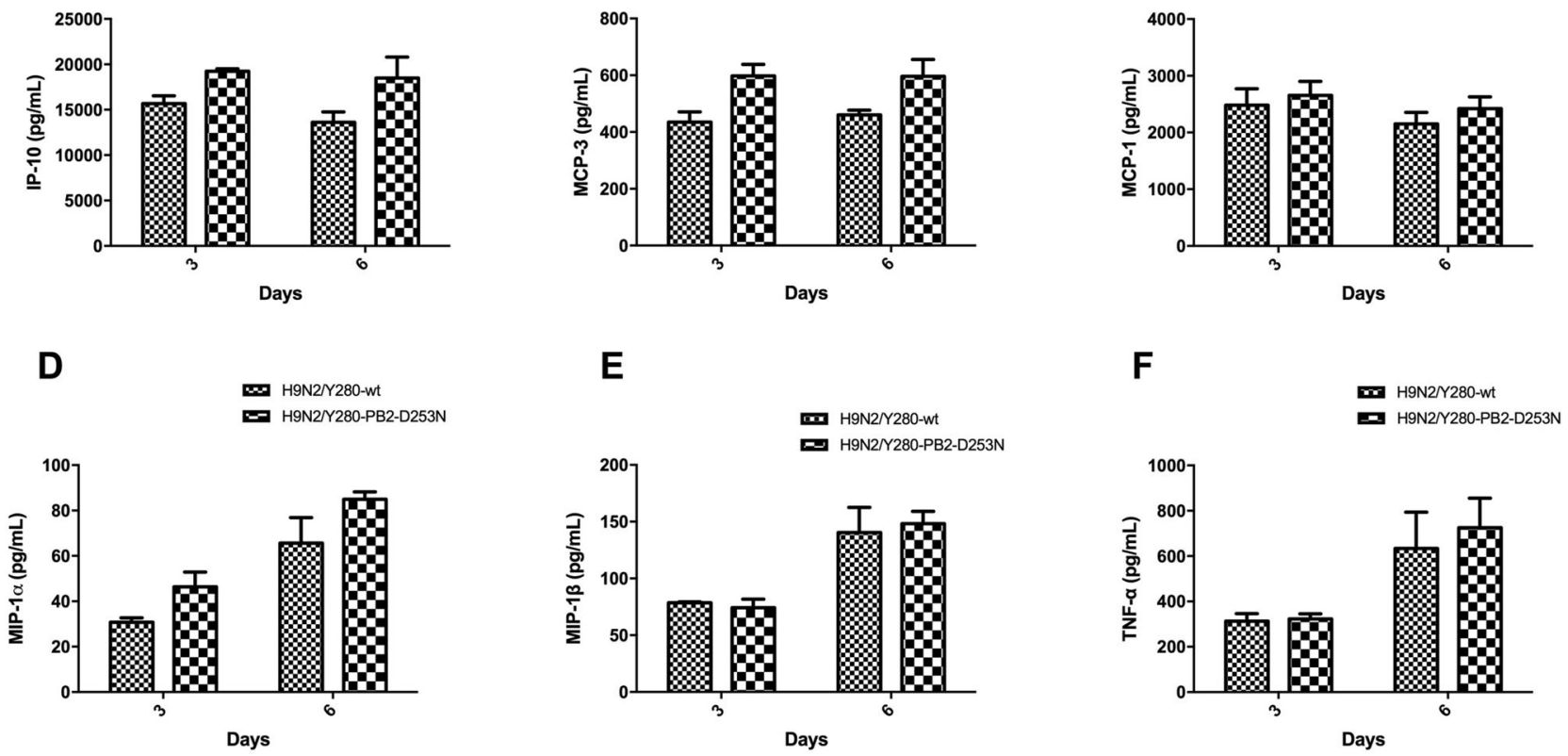

Fig. 4 Cytokine expression in the lungs of mice infected with H9N2/ Y280 and the D253N mutant in PB2. The lungs of virus-infected mice were collected from days 3 and 6 postinoculation, and A IP-10, B MCP-3, C MCP-1, D MIP-1 $\alpha, \mathbf{E}$ MIP- $1 \beta$, and F TNF- $\alpha$ levels were

measured by bead ELISAs. Results from each time point are expressed as means \pm standard deviations of three infected mice $(\mathrm{n}=3)$.

mammalian hosts (Wang et al. 2016; Yamada et al. 2010). In this study, we showed that the D253N mutation in PB2 contributed to increased polymerase activity and viral replication in human cells at $37{ }^{\circ} \mathrm{C}$ using another H9N2 lineage different from that in our previous studies. These results were consistent with the temperatures at which we identified this mutation in MDCK cells, suggesting that the D253N mutation may be responsible for adaptation of the virus at $37{ }^{\circ} \mathrm{C}$, i.e., the temperature of the lower respiratory tract. However, unlike the Q591K mutation, H9N2 virus with only the D253N mutation in PB2 did not showed enhanced viral replication or cytokine induction in mice, despite causing more weight loss on days 4-7 compared with that in the wt control. These results explained why we could not find the D253N mutation in human isolates because this mutation did not provide a long-lasting advantage for selection among all other mutations for mammalian adaptation, similar to the wt isotype.

Although the H9N2 virus with the D253N mutation in PB2 caused significantly more weight loss in the mice compared with the wt control, the viral loads and cytokine levels in the lungs were not correlated with differences in pathogenesis. We previously showed that the E627K and Q591K mutations in PB2 could increase the influx of neutrophils compared with the wt H9N2 virus (Wang et al. 2016). Human neutrophils are the most abundant leukocytes in the body and rapidly respond to both bacterial and

viral infections (Németh and Mócsai 2016; Parkos 2016). However, excessive infiltration of neutrophils into the lungs is also correlated with lung inflammation and immunopathology, which causes pneumonia (De Filippo et al. 2014; Sugamata et al. 2012). Whether the virus with the D253N mutation in PB2 attracts more neutrophils or other immune cells will need to be further investigated.

PB2 is a viral polymerase with 759 amino acid residues composed of an $\mathrm{N}$-terminal domain, a middle domain, a cap-binding domain, a 627 domain, and an NLS domain (Lo et al. 2018). Residue 253 is located in the middle domain, which has four intertwining helices spanning amino acid residues 251-316. The structural analysis showed that this residue is not in close contact with PB1 or PA but is involved in a global domain reorientation, suggesting that this domain serves as a bridge to link the $\mathrm{N}$-terminal domain and other domains (Lo et al. 2018). Our results further showed that the D253N mutation in this region enhanced the replication of the avian influenza virus through adaptation in mammalian cells. We did not show that changing the aspartic acid residue to asparagine would alter the structure of the middle domain. However, switching of the charge from negative (D) to neutral (N) may affect the interaction of PB2 with other components of ribonucleoprotein complex (RNP), which could increase viral transcription; additional studies are needed to support this hypothesis. Moreover, similar results were 
observed for two other H9N2 viruses: A/Quail/Hong Kong/ G1/97 (H9N2/G1) and A/Duck/Hong Kong/Y280/97 (H9N2/Y280), in which their genetic backgrounds were highly distinct, suggesting that this functional role was not strain specific (Mok et al. 2011). Interestingly, another study showed that the T271A mutation in PB2, which is also located in the middle domain, enhances polymerase activity but not virulence in mice (Bussey et al. 2010).

Taken together, our results supported that the D253N mutation in the middle domain of PB2, similar to mutations at the 627 and NLS domains, specifically contributed to the replication process of avian influenza viruses in human cells.

Acknowledgements This project was supported by the Science Research Project of the Guangdong Province (Grant no. 2016A050503047), Health and Medical Research Fund (Grant No. 12111832), Guangzhou Medical University High Level University Construction Project Funding and Research Grants Council of the Hong Kong Special Administrative Region, China, through the Theme Based Research Scheme (Ref: T11-705/14N).

Author Contributions JZ, RS, and CKPM designed the study, HA and CKPM performed the experiments; JZ, XJ, RJ, and YW analyzed the data, JZ and CKPM wrote the main manuscript. All authors read and approved the final manuscript.

\section{Compliance with Ethical Standards}

Conflict of interest We declare that no authors have conflict interests.

Animal and Human Rights Statement All institutional and national guidelines for the care and use of laboratory animals were followed.

\section{References}

Bussey KA, Bousse TL, Desmet EA, Kim B, Takimoto T (2010) PB2 residue 271 plays a key role in enhanced polymerase activity of influenza A viruses in mammalian host cells. J Virol 84:4395-4406

Chan MC, Cheung CY, Chui WH, Tsao SW, Nicholls JM, Chan YO, Chan RW, Long HT, Poon LL, Guan Y, Peiris JS (2005) Proinflammatory cytokine responses induced by influenza A (H5N1) viruses in primary human alveolar and bronchial epithelial cells. Respir Res 6:135

Chan MC, Chan RW, Chan LL, Mok CK, Hui KP, Fong JH, Tao KP, Poon LL, Nicholls JM, Guan Y, Peiris JS (2013) Tropism and innate host responses of a novel avian influenza A H7N9 virus: an analysis of ex vivo and in vitro cultures of the human respiratory tract. Lancet Respir Med 1:534-542

Cheung CY, Poon LL, Lau AS, Luk W, Lau YL, Shortridge KF, Gordon S, Guan Y, Peiris JS (2002) Induction of proinflammatory cytokines in human macrophages by influenza A (H5N1) viruses: a mechanism for the unusual severity of human disease? Lancet 360:1831-1837

De Filippo K, Neill DR, Mathies M, Bangert M, McNeill E, Kadioglu A, Hogg N (2014) A new protective role for S100A9 in regulation of neutrophil recruitment during invasive pneumococcal pneumonia. FASEB J 28:3600-3608

de Jong MD, Simmons CP, Thanh TT, Hien VM, Smith GJ, Chau TN, Hoang DM, Chau NV, Khanh TH, Dong VC, Qui PT, Cam BV,
Ha do Q, Guan Y, Peiris JS, Chinh NT, Hien TT, Farrar J (2006) Fatal outcome of human influenza A (H5N1) is associated with high viral load and hypercytokinemia. Nat Med 12:1203-1207

Gao HN, Lu HZ, Cao B, Du B, Shang H, Gan JH, Lu SH, Yang YD, Fang Q, Shen YZ, et al. (2013) Clinical findings in 111 cases of influenza A (H7N9) virus infection. N Engl J Med 368:2277-2285

Hatta M, Gao P, Halfmann P, Kawaoka Y (2001) Molecular basis for high virulence of Hong Kong H5N1 influenza A viruses. Science 293:1840-1842

Hatta M, Hatta Y, Kim JH, Watanabe S, Shinya K, Nguyen T, Lien PS, Le QM, Kawaoka Y (2007) Growth of H5N1 influenza A viruses in the upper respiratory tracts of mice. PLoS Pathog 3:1374-1379

Li H, Cao B (2017) Pandemic and avian influenza A viruses in humans: epidemiology, virology, clinical characteristics, and treatment strategy. Clin Chest Med 38:59-70

Liem NT, Tung CV, Hien ND, Hien TT, Chau NQ, Long HT, Hien NT, le Mai Q, Taylor WR, Wertheim H, Farrar J, Khang DD, Horby P (2009) Clinical features of human influenza A (H5N1) infection in Vietnam: 2004-2006. Clin Infect Dis 48:1639-1646

Lo CY, Tang YS, Shaw PC (2018) Structure and function of influenza virus ribonucleoprotein. Subcell Biochem 88:95-128

Mok KP, Wong CH, Cheung CY, Chan MC, Lee SM, Nicholls JM, Guan Y, Peiris JS (2009) Viral genetic determinants of H5N1 influenza viruses that contribute to cytokine dysregulation. J Infect Dis 200:1104-1112

Mok CK, Yen HL, Yu MY, Yuen KM, Sia SF, Chan MC, Qin G, Tu WW, Peiris JS (2011) Amino acid residues 253 and 591 of the $\mathrm{PB} 2$ protein of avian influenza virus A H9N2 contribute to mammalian pathogenesis. J Virol 85:9641-9645

Mok CK, Lee HH, Chan MC, Sia SF, Lestra M, Nicholls JM, Zhu H, Guan Y, Peiris JM (2013a) Pathogenicity of the novel A/H7N9 influenza virus in mice. MBio pii:e00362-13

Mok CKP, Lee HHY, Lestra M, Nicholls JM, Chan MCW, Sia SF, Zhu H, Poon LLM, Guan Y, Peiris JSM (2013b) Amino-acid substitutions in polymerase basic protein 2 gene contributes to the pathogenicity of the novel A/H7N9 influenza virus in mammalian hosts. J Virol 88:3568-3576

Németh T, Mócsai A (2016) Feedback amplification of neutrophil function. Trends Immunol 37:412-424

Parkos CA (2016) Neutrophil-epithelial interactions: a double-edged sword. Am J Pathol 186:1404-1416

Perrone LA, Plowden JK, García-Sastre A, Katz JM, Tumpey TM (2008) H5N1 and 1918 pandemic influenza virus infection results in early and excessive infiltration of macrophages and neutrophils in the lungs of mice. PLoS Pathog 4:e1000115

Sugamata R, Dobashi H, Nagao T, Yamamoto K, Nakajima N, Sato Y, Aratani Y, Oshima M, Sata T, Kobayashi K, Kawachi S, Nakayama T, Suzuki K (2012) Contribution of neutrophilderived myeloperoxidase in the early phase of fulminant acute respiratory distress syndrome induced by influenza virus infection. Microbiol Immunol 56:171-182

Wang C, Lee HHY, Yang ZF, Mok CKP, Zhang Z (2016) PB2Q591K mutation determines the pathogenicity of avian H9N2 influenza viruses for mammlian species. PLoS ONE 11:e0162163

Yamada S, Hatta M, Staker BL, Watanabe S, Imai M, Shinya K, Sakai-Tagawa Y, Ito M, Ozawa M, Watanabe T, Sakabe S, Li C, Kim JH, Myler PJ, Phan I, Raymond A, Smith E, Stacy R, Nidom CA, Lank SM, Wiseman RW, Bimber BN, O'Connor DH, Neumann G, Stewart LJ, Kawaoka Y (2010) Biological and structural characterization of a host-adapting amino acid in influenza virus. PLoS Pathog 6(8):e1001034

Zhou J, Wang D, Gao R, Zhao B, Song J, Qi X, Zhang Y, Shi Y, Yang L, Zhu W, et al. (2013) Biological features of novel avian influenza A (H7N9) virus. Nature 499:500-503 